\title{
Transaction Obstacle and Its Governance: A Case Study on the "Stumbling Blocks" of Entrepreneurship
}

\author{
Yu Cheng1, Jun Wen ${ }^{2 *}$, Yaping Xie ${ }^{3 *}$ \\ ${ }^{1}$ School of Management, Xiamen University, Xiamen, China \\ ${ }^{2}$ School of Economics and Management, Nanjing University of Science and Technology, Nanjing, China \\ ${ }^{3}$ School of Economics and Management, Fuzhou University, Fuzhou, China \\ Email: chengyu@xmu.edu.cn, ^njustwen@126.com, ^fdxyp@163.com
}

How to cite this paper: Cheng, Y., Wen, J., \& Xie, Y. P. (2020). Transaction Obstacle and Its Governance: A Case Study on the "Stumbling Blocks" of Entrepreneurship. Open Journal of Business and Management, 8, 1315-1338.

https://doi.org/10.4236/ojbm.2020.83085

Received: March 24, 2020

Accepted: May 26, 2020

Published: May 29, 2020

Copyright $\odot 2020$ by author(s) and Scientific Research Publishing Inc. This work is licensed under the Creative Commons Attribution International License (CC BY 4.0).

http://creativecommons.org/licenses/by/4.0/

\begin{abstract}
Through case study, this essay focuses on "transaction obstacle" which blocks entrepreneurship, and finds that entrepreneurs may establish complete business system by detecting and governing those key transaction obstacles. Therefore, the essay hypothesizes that transaction obstacle is a key construct in entrepreneurial process and the excellence of transaction obstacle governance is positively correlated with entrepreneurial success. The research initially presents both the concept of transaction obstacle and the concept of transaction obstacle governance, and thus adds new knowledge to the entrepreneurial process theory.
\end{abstract}

\section{Keywords}

Transaction Obstacle, Entrepreneurial Process, Entrepreneurial Failure, Online Platform, Alibaba, Transaction Obstacle Governance

\section{Introduction}

Starting a new business from scratch usually encounters lots of "stumbling blocks", namely, obstacles which lead to the dooms of many entrepreneurial careers. For these years, this sort of entrepreneurial failure can be especially observed in the process of online entrepreneurship (Lin \& Wang, 2019), where all the stakeholders have to be involved in complicated transaction relations based on modern internet-based information links (Steininger, 2019), which obliges the platform to face multiple factors they can't bridge over that constitute strikingly threats to their business lives. 
No doubt, entrepreneurial failure is by no means what entrepreneurs expect; how to avoid failure is always their earnest concern (Lin \& Wang, 2019). Then naturally, identifying those "stumbling blocks" among the business structure and finding effective ways to kick them off, become a meaningful work for helping startups to survive. In this regard, the noted online enterprise Alibaba E-commerce Trading Platform (abbreviated as "Ali E-commerce" below), as a successful survivor who once suffered from those obstacles, demonstrated some valuable experiences in its entrepreneurial history for us (Hu \& Chang, 2019).

Nowadays, Ali E-commerce is becoming an influential online platform servicing for more than 711 million active purchasers in 2019 (Alibaba Group, 2019), which may make it currently the world's largest e-commerce trading platform, with its sheer size and scope even dwarf that of its closest competitors Amazon, the world's second e-commerce platform (Chow, 2020). However, if we look back to its fledging time, we can only find a business newbie who had nothing but a dream. Certainly there were countless sellers and buyers who had the desires to trade on line in that time, but absolutely it was a toughest business task for Ali E-commerce to urge them to choose its platform to do so. That was because you can't imagine that the following context virtually surrounded every emerging e-commerce platform at the advent of internet commerce (e-commerce) in the early 2000s: the sellers always plunged into the difficulty to figure out where to go when they were run after by every ambitious platform both from online and offline who were doing their every efforts to allure them to be their exclusive partners; the buyers were always in a horror that they could not see any real items their want to buy from the scenarios the platforms presented (Bleier, Harmeling, \& Palmatier, 2018); both the sellers and the buyers were desperate once any side of them broke up their promises on trading; there were still no way to deliver those goods efficiently even when they finally gathered in the platform to bargain; and especially, the sellers captured by the platforms often couldn't find a reliable pricing strategy to balance their benefit with the platform to make profit in certainty (Chen, Nan, \& Li, 2018).

Under such tough business surroundings of that time, wherever Ali E-commerce wanted to go, there were big "stumbling blocks" just awaiting it. How could Ali E-commerce, as a weak startup, find out a unique way to successfully respond to all those challenges to grow up? Till now there are still insufficient explanations about it.

This paper will showcase that, among Ali E-commerce's entrepreneurial recipes, wisely identifying and overcoming the obstacles that hindered the transactions between its stakeholders really deserves being learned from. From the following analysis, you will find that Ali E-commerce might be pretty more sober than its competitors on this aspect and therefore gained advantage over his rivalries.

Unfortunately, today still witnesses many startups are repeatedly tortured by the obstacles distributed among their business structure. Executing a rounded 
case analysis to explicitly interpret this phenomenon will definitely give those puzzled entrepreneurs a timely helping hand. Therefore, this research will focus on the obstacle problem by a case study of Ali E-commerce and suggest some new ideas for entrepreneurship.

The result indicates that the establishment process of Ali E-commerce is in fact identical to conquering transaction obstacles (TO). By effective governance of transaction obstacles, Ali E-commerce is able to set up effective business system. The research suggests that transaction obstacle governance (TOG) has general significance to entrepreneurial success.

Next, this essay will pass through three parts: the first part is literature review, which provides the starting point of the discussion; the second part adopts qualitative method to do case study and proposes the hypotheses; the final part presents the contributions and limitations of this work.

\section{Literature Review}

The process of business establishment involves synthesizing multiple complex factors; therefore, the analysis of those key influential factors has long been emphasized in the theoretical studies on entrepreneurship. Cartner (1985) believes that an entrepreneurial process completes by integrating four major components: characteristics of the entrepreneur, the environment, the entrepreneurial process and the organization. Moore (1986) argues that personal, sociological, and environmental factors give birth to a new enterprise. While Timmons (1999) proposes that business opportunities, as well as the resources and the entrepreneur, are the most important driving forces of entrepreneurship and that these components always maintain dynamic equilibrium in different phases of entrepreneurship. Bygrave (1997), by synthesizing the points of Moore and Timmons, advocates that a would-be entrepreneur should manage to rein a wide range of crucial factors such as the individual, the opportunity, the environment, the resources and so on. These research achievements together have gradually clarified the key factors of entrepreneurship and provided theoretical framework for entrepreneurial process theory.

Nevertheless, among the researches concerning these factors, the generalization of the obstructive factors, the "stumbling blocks" of entrepreneurship, almost has not been systematically touched on yet. In fact, the running of everything involves the synergy of both stimulative and obstructive factors, which also applies to entrepreneurship without exception. Thus the obstructive factors should not be neglected in the research of entrepreneurial process; otherwise, there will be a disappointing gap in entrepreneurial process theory.

Some scholars have already noticed this point. For example, Churchill and Lewis (1983) observe that the depletion of cash flow, capital flight, unsuccessful strategic adjustments, along with management shocks and the lack of initiative can lead to entrepreneurial collapse. Fogel et al., 2006 argue that institutional obstacles often hinder entrepreneurship. Bitzenis \& Nito (2005) find that entre- 
preneurs face many serious obstacles including unfair competition, changes of tax procedures, lack of financial resources and some issues about public order in Albanian entrepreneurship during the country's economic transformation. Bhosale \& Bhola (2014) find that in India, increasingly fierce competition, inflation, the power of large enterprises, declining productivity, union shocks, high capital costs, incomplete government regulations, and other factors that are difficult for entrepreneurs to control often inhibit a startup.

Some scholars point out that the obstructive factors that threaten the success of entrepreneurship usually exist in the early stage of entrepreneurship (Cacciotti et al., 2016; Morris et al., 2012). Dewald \& Bowen (2010) argue that situational threats may cause promising business opportunities to be abandoned. Kollmann, Stöckmann, \& Kensbock (2017) point out that the existence of obstacles can arouse entrepreneurs' fear of failure, which in turn dampens their assessment and exploitation of entrepreneurial opportunities.

These findings give us enough reasons to raise our attention to the obstacles that affect the success of entrepreneurship. An in-depth study of this topic may offer people a better understanding of the determinants of entrepreneurial success or failure.

Fogel et al. (2006) launch their analysis of obstructive factors influencing entrepreneurship in the facet of institutional obstacles. They find that many of the impediments in entrepreneurship germinate in the institutional environment. They believe that though insufficient protection of property rights, liquidity restrictions, cumbersome and expensive regulation, and systems that hinder information flow are not prominent in some developed economies, they tend to constitute very serious entrepreneurial obstacles in many poor countries and regions as well as some developing countries. This research line focusing on the institutional environment factors that influence entrepreneurship has been a main research perspective operated by most scholars (Bitzenis \& Nito, 2005; Bhosale \& Bhola, 2014).

However, entrepreneurship itself is a complicated and integrated process (Fogel et al., 2006). Beyond the outer circumstances, the complex process of entrepreneurship itself which runs within the circumstances should not be overlooked. Unfortunately, the existing researches do have overlooked it. Therefore, logically it especially deserves exploring whether there are some crucial obstructive factors within entrepreneurial process itself. For years the authors have kept on searching for the relevant topics like "business/entrepreneurial obstacles/barriers/problems", "business/entrepreneurial processes", "business/entrepreneurial failure", etc., at the data base of PAO, ABI/INFORM Complete and EBSCO both in management and in economic fields, yet have seldom found articles that exactly touch on the obstacles within entrepreneurial process. Even though, a recent paper written by Sellami et al. (2019) propose a similar perspective, talking on the obstacles connected with the "exception" during business process that usually cause business suspending and failure. Their finding somewhat supports the authors' guess that 
obstacles in business process deserve being taken into account. This study attempts to make a preliminary exploration in this regard.

\section{Research Design}

\subsection{Research Methods and Team Organization}

As mentioned above, whether there are still some key obstacles neglected in the process of entrepreneurship itself nearly remains somewhat untapped by existing theories. This situation means that researchers can hardly speak out any concrete features of those obstructive factors hiding in the business process, and therefore, this research must do some initiative exploring work to discover them. The point lies in how to identify, capture and refine the obstructive factors into meaningful constructs.

When the basic construct is still a potential variable that need to be dig out and further discussed by academics, the situation is just like that when people want to get the knowledge of where and how COVID-19 reproduces itself in a person's body, doctors must observe the tiny details about how COVID-19 lives in one single person's body through CT or even autopsy. Cardoni, Kiseleva, \& Lombardi (2020) argue that under such context case study has the advantage of detailed investigation and intelligible expression to readers over quantitative approach. Javaid \& Hydera (2018) especially emphasize that when a researcher intends to understand a previously unexplored phenomenon and develop theory to explain it case study accompanied with grounded method promoted by Eisenhardt is ever effective to cope with those primary data which is qualitative in nature.

Su et al. (2020) also claim that case study is suitable to analyze the entrepreneurial activities which are highly dynamic and complex. Evidently, it is appropriate to use the method of case study and grounded analysis to execute qualitative research (Santos \& Eisenhardt, 2005; Eisenhardt \& Graebner, 2007; Van Burg \& Romme, 2014). This kind of method is good at extracting and inducing essences from raw business materials, which will be helpful to establishing meaningful constructs for further statistic analyses.

Moreover, considering that varied obstacles may distribute in every path and every phase during a startup's growth up (Sellami et al., 2019), surely it is necessary to disclose how they distribute. Logically, this means that observing a historical sample may be very ideal as it is nearly the most convenient, reliable and effective way for researchers to get rounded information accumulated in an entrepreneurial process. Sellami et al. (2019) initiate a new method of using business $\log$ (storing execution traces) to reap up the data about the obstacles, yet this method need you have access to a business process. Apparently, this is a feasible method only when researchers are given special opportunity to take part in an entrepreneurial process; otherwise, once having no such opportunity, researchers have to give it up. Even though, this method gives the authors a helpful implication that the authors can try to draw on historical records easy to find, 
such as the formal archives of an entity, the more reliable substitute of a business $\log$, to get the similar or even better data-collecting effect. Accordingly, we finally find that the most appropriate method is to employ a qualitative analysis based on grounded theory and supported by historical document of an entrepreneurship to dissect the entrepreneurial activities of case enterprise, and then we decide to do so in this work.

To ensure the quality of the research, a research team is set up. The team consists of three groups led respectively by three teachers assisted by six graduate or undergraduate students. Two of the groups act as code-analyzing groups, taking the task of data collection as well as coding and data analysis, while the other one acts as quality-controlling group, i.e. a dedicated challenger and program supervisor, free from data collection as well as coding and analysis, taking the responsibility of assuring robust credibility and reliability throughout the research process. During the data collection, two code-analyzing groups first collect data parallel and independently, and then establish a common database through comparison and verification. In the data coding and analysis, the groups also adopt parallel and independent analysis, and then operate mutual cross-examination and discussion to reach a consensus. When the opinions of the groups differ, the groups are required to fully defend their opinions; the openness of the opinions and defenses is maintained throughout the research process, and the collective decisions are made at the end stage of finalization.

\subsection{Object Choice}

This research selects the entrepreneurial process of Ali E-commerce as the object. For the convenience of research, herein this study first defines Ali E-commerce as the integrated trade system of three business divisions including Taobao.com, Tmall Mall and Yitao.com from 1999 to 2009, which covers almost all forms of trades, such as wholesale, retail and auction, both domestically and internationally. According to Alibaba Group's public statement, this system is the core part of all its businesses (Alibaba Group itself calls it "core e-commerce"). Ali E-commerce's success has laid the foundation for all the businesses Alibaba Group engages in today.

According to Alibaba's annual public reports and the official releases of the memorabilia, the history of Ali E-commerce can be roughly divided into two stages. The start-up period is 1999-2002. During this time, the concept of "building a future commercial infrastructure" was put forward, as well as the vision of "letting customers meet, work and live at Alibaba", but the future seemed to be rather uncertain. In 2003-2009, Ali E-commerce entered the critical period of entrepreneurship, attracting a large number of SMEs and consumers into its platform (Meet at Alibaba) through a series of unique entrepreneurial initiatives, which solved the problem of customer resource accumulation and promoted online transactions (Work at Alibaba). The initial entrepreneurial practices successfully built a complete business system, gradually turning the obscure blueprint 
and vision of the early period into reality, and thus allowed Ali E-commerce to grow rapidly into the largest retailing body in Asia.

In short, Ali E-commerce is one prominent representative of those firms who successfully complete the entrepreneurial process from scratch. Since its entrepreneurial process lasts for about 10 years and contains a wealth of content, virtually it is an ideal sample for the study of the entrepreneurial process from the perspective of purposive sampling. Therefore, this study chooses Ali E-commerce as the research object.

\subsection{Analysis Unit}

Through the preliminary analysis of the data, this study finds that Ali E-commerce has established a complete business system from scratch during the entrepreneurial process. The system can be treated as a systematic transaction structure (Figure 1), which includes: 1) the transaction between Ali E-commerce and the wait-and-see sellers (hereinafter also referred to as "A-B transaction"), in which Ali E-commerce exchanges for the "entry" of the wait-and-see sellers by "X Service"; 2) the transaction between Ali E-commerce and the wait-and-see buyers (hereinafter also referred to as "A-C transaction"), in which Ali E-commerce exchanges for the "visit" of the wait-and-see buyers by "Y service"; 3) the transaction between the registered sellers and the visiting buyers who have already entered the Ali E-commerce (hereinafter also referred to as $\mathrm{B}^{\star}-\mathrm{C}^{\star}$ transaction), in which the buyers and the sellers exchange money and merchandises; 4) the transaction between Ali E-commerce and the profitable sellers (hereinafter also referred to as "A-B ${ }^{* *}$ transaction"), in which Ali E-commerce exchanges "Z $Z$ service" for "revenue" from the profitable sellers.

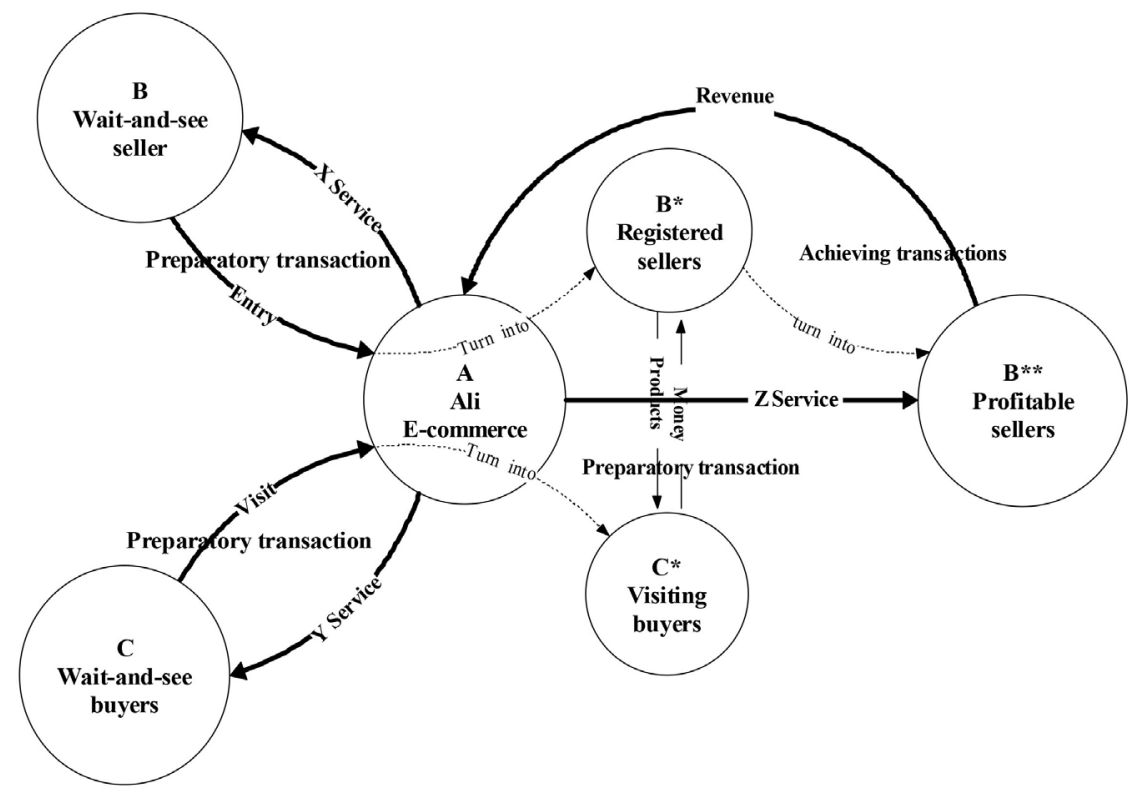

Figure 1. The complete business system of Ali E-commerce, a whole set of transaction structure. 
According to Cheng (2004), the former three kinds of transactions are necessary for getting ready to capturing profit, thus it is reasonable to name them "preparatory transactions"; while the latter transaction brings profit to the enterprise and thus can be called "achieving transactions". These two groups of transactions constitute the complete trading system of Ali E-commerce. Ever since this system has been running as a positive commercial cycle, Ali E-commerce has begun to develop rapidly, which illustrates that the establishment of the system, an effective transaction structure, marks the entrepreneurial success of Ali E-commerce.

In this way, the above four transactions objectively demonstrate that they are the basic units of the Ali E-commerce business system. Therefore, the study finally decides to set the above-mentioned "transactions" as the analysis units. This approach provides a clearly organized framework for collecting and processing data for this study.

\subsection{Embedded Multiple Subcases}

Once a transaction is chosen as an analysis unit, the study can conduct comparative research and correlation analysis between the transactions after observing individual one. Eisenhardt $(1989,1991)$ argues that a single case study is not really a "single" case because it needs to group data, look for similarities and differences among groups, and perform cross-group data analysis. Since each of the Ali E-commerce's transactions has its relatively individual features, they are virtually independent with each other. Thus, this research becomes a study of multiple transaction subcases within a single research object, or essentially a multiple case study. Chinese scholar Han et al. (2017) call this situation as "subcase-embedded study of a single case", but during the study they still follow the "replication logic", the method used in multiple case study (it is clear that the key point to this sort of research does not lie in how to name it but in whether it is possible to use the "replication logic"). This article temporarily adopts the term of Chinese scholars to refer to this project as a study of single case embedded with multiple subcases analysis, and then carries out cross-subcase analysis on the basis of each transaction research. This allows the study to manipulate the replication and extending logic used in multi-case studies (Eisenhardt, 1989, 1991; Lü, 2014), and thereafter the robustness of logical induction are enhanced.

\section{Data Collection}

Alibaba Group attaches great importance to information filing and disclosure. Its official website publishes a very sufficient, complete and authoritative database concerning the history and current status of Ali E-commerce, including not only all those documents published in Hong Kong in China and US securities markets over the years, such as business review reports, working reports, annual financial reports, corporate governance reports, comprehensive reports on sus- 
tainable development, etc., but also other important supplement data, e.g., announcement of major affairs, keynote speeches of senior managers and company press releases, and so on. After analyzing the data, the research team believes that these publicly available documents provide sufficient, reliable and authoritative information for analyzing the entrepreneurial process of Ali E-commerce, and therefore decides to use them to conduct research. In addition, due to Ali E-commerce's outstanding commercial influence on a global scale, many Chinese and foreign experts and scholars have also conducted research about it by writing monographs and journal articles. This research also collects some rigorous ones of them and conducts triangular verification upon them to enrich the database about Ali E-commerce.

\section{Reliability and Validity Control}

This study pays particular attention to ensuring research reliability and validity through comprehensive application of various techniques. Through data triangulation, especially against those data both in Chinese versions and in English versions published at different times, this study strives to ensure the objectivity and authenticity of the research data. By setting up a quality-controlling group within the research team, this study strengthens the process of cross-examination, rectification, strives to rule out the individual's thinking limitations, and then ensures the reliability of construct formation and of variable relationship development. Through using the horizontal cross-subcase analysis and implementing the replication and extending logic, this study executes appropriate procedures for inductive reasoning. Drawing on the capacity of text analysis software in handling massive data, this study also utilizes software to help processing data to ensure the objectivity and accuracy of analysis. Moreover, the study manages to reap up saturated evidences to support the reasoning and actively draw on the relevant classical theories to verify the findings, so that the internal validity and external validity can be cemented.

\section{Analysis and Discovery}

\subsection{Data Coding}

In order to explore the unknown in the process of Ali E-commerce's venturing, this study adopts grounded analysis method. According to the general coding procedure, this study divides the coding process into several stages: focused coding, axial coding and theory coding.

Focused coding requires each group to code independently and parallel. In order to prevent information from missing, it is required to encode the text piece by piece. For any paragraph with substantial meaning, it is necessary to extract the code. If there is a plurality of meaningful information within a piece of text, it is necessary to extract multiple codes. To reduce information distortion, this study also requires using in vivo code whenever possible. Then, this study brings together all the codes gained by the two coding groups to form a preliminary ba- 
sic code pool with 258 codes. Further, in reference to the method of Gilbert (2005), the study invites a second reader who has no knowledge of the original coding and research purposes of this study to perform a cross check on the original codes. In this process, the original codes that do not contradict with each other are retained, and then the retained codes are discussed piece by piece in the whole team. Further, the similarities and differences of the retained codes are carefully discriminated, and the codes that are not related to the entrepreneurial process are deleted. After these efforts, a total of 188 focused codes are reaped up. Table 1 illustrates the formation of focused coding.

In the axial coding phase, the study still advances in groups. After each group completes the coding individually, the team pools together all the data they have got for further cross comparison and consensus.

Finally, this study identifies the "entrepreneurial obstructive factor" as the core category, and then groups to carry out theory coding. Every group pays much emphasis to the enhancement of the density, the degree of variation and the theoretical consistence of the constructs.

Through the above processes, including argument exchanges and challenges with each other between groups as well as collective decision-makings in the whole team, the study finally gets 65 secondary categories, and then summarizes them into six first-level categories: transaction objectives, key obstructive factors, key measures, effect evaluation, strategy improvement, and entrepreneurial success. Finally the study extracts two key constructs and a new entrepreneurial process model.

\subsection{Cross-Subcase Comparison: The Entrepreneurial Logic and Evidence Chain}

As mentioned above, Ali E-commerce must build the four sub-transactions shown in Figure 1, after which the entire business system can take shape. However, the study finds that there is a dominant obstructive factor in each sub-transaction, and every factor seems to be the "stumbling block" between both of the parties in the process of transaction, and seriously impedes the realizing of the sub-transaction.

Ali E-commerce first has to try to accomplish A-B sub-transaction. However, the study finds that "channel threshold competition (CTC)" among various channels

Table 1. An example of focused coding.

\begin{tabular}{|c|c|}
\hline Focused coding & Original data \\
\hline $\begin{array}{l}\text { Make it easy to do business; } \\
\text { the foundational logic underlying } \\
\text { our business decisions; create value; } \\
\text { solve the problems of society; } \\
\text { generate revenue. }\end{array}$ & $\begin{array}{l}\text { The belief in our mission-to make it easy to do } \\
\text { business anywhere-is the foundational logic } \\
\text { underlying our business decisions. } \\
\text { We believe that we do not create value if we do not } \\
\text { solve the problems of society, and if we do not create } \\
\text { value for our customers, then the company will } \\
\text { not be able to generate any revenue, much less profits, } \\
\text { from customers (Alibaba Group, 2018). }\end{array}$ \\
\hline
\end{tabular}


like offline stores, eBay, Amazon and 1688 that are all vying for businesses constitutes a prominent obstacle factor. This makes the wait-and-see sellers repeatedly ponder on whether to settle in Ali E-commerce. Apparently, CTC seriously threatens the business invitation plan of Ali E-commerce, and has become a huge stumbling block to A-B sub-transaction.

Meanwhile, Ali E-commerce also has to do the deal of A-C sub-transaction. However, as Kwak, Zhang and Yu (2019) point out, during that period in China's e-commerce, the existence of fake goods production, fraudulent sales and other phenomena, seriously troubles consumers. This situation stimulates "transaction security concerns (TSC)" among the wait-and-see buyers, which constitutes a severe obstructive factor. Consequently, TSC hinders the wait-and-see buyers from visiting e-commerce platforms like Ali E-commerce, seriously retards the consumers from gathering at Ali E-commerce, and becomes a huge stumbling block to A-C sub-transaction.

Even though the sellers and buyers have gathered at Ali E-commerce, they still need to make the deal of $\mathrm{B}^{\star}$ - $\mathrm{C}^{\star}$ sub-transaction. Yet another kind of obstructive factor, namely the severe "information asymmetry and trading condition limitation (IATCL)", is found here. Because the buyers and sellers do not trade on the spot at Ali E-commerce, there is an information asymmetry problem about the real situation of the goods; the buyers, in particular, absolutely become the weak who lack sufficient information due to both having no chance to check goods face to face with the sellers and having no way to communicate with them. Accordingly, their minds often fall in a nervous state, in which they do want to buy but dare not to do so. On the other hand, for those consumers who prefer online shopping and yearn for trying e-commerce, other problems such as insufficient funds, high logistics costs, return difficulties as well as other limits in transaction conditions may arise and bar the transaction likewise. All these obstructive factors are unavoidable "stumbling blocks" between the buyers and sellers; they significantly influence whether Ali E-commerce can achieve the mission of intermediating transactions. So Ali E-commerce must effectively deal with IATCL.

Finally, Ali E-commerce has to earn financial return from its $\mathrm{A}-\mathrm{B}^{* *}$ subtransaction. Here, in order to be able to get long term financial returns from the sellers, Ali E-commerce must create opportunities for them to make money. However, the several stumbling blocks in all above sub-transactions actually jointly produce "uncertainty of the opportunity to make money (UOMM)", which further constitutes a prominent obstructive factor, a huge stumbling block to $\mathrm{A}-\mathrm{B}^{* *}$ sub-transaction.

In summary, the study finds that there are recurring obstructive factors in all the Ali E-commerce sub-transactions, and each one plays a similar role like stumbling block in each sub-transaction, seriously impeding the progress of each important transaction. Moreover, throughout the entire entrepreneurial process, these stumbling blocks also overlap with each other to constitute an obstructive factor system, and then induce systemic threats to the whole transaction structure. 
In terms of the causes of these obstructive factors, CTC originates mainly from the optimal trade-off from the wait-and-see sellers, TSC from the buyer's risk awareness, and IATCL from the non-uniformity nature of the transaction itself. Since both the interest trade-off of the trading parties and the non-uniformity of the transaction are natural things in any transaction, it seems that they are all endogenous from the transaction itself.

Thus, these obstructive factors exhibit the following basic characteristics: first, they are obstacles like stumbling blocks that erect between both parties within a transaction and impede a business from dealing with its business partners and customers; second, they almost always accompany transactions, natively inflicting the risk of failure on almost any transaction. In view of their strong transaction-related attributes and negative attributes, this study summarizes them as a key construct "transaction obstacle (TO)". Table 2 shows the data evidence of key transaction obstacle (KTO) in each sub-transaction.

Furthermore, this study in depth analyzes the entrepreneurial measures of Ali E-commerce. The study finds that although the specific entrepreneurial activities of Ali E-commerce are various and complex, they can be grouped into three core types of measures (service $\mathrm{X}, \mathrm{Y}$ and $\mathrm{O}$ in Figure 2).

The first one is "implementation of the lower threshold policies (ILTPs)" which is a low-cost policy in character of free entry or quasi-free entry for the buyers and sellers (especially for the sellers) who are meditating on whether or not to choose Ali E-commerce platform. This type of measures mainly aims at the stumbling block of CTC. The data show that Taobao.com established in 2003 by Ali E-commerce was immediately free to all users. The effect was encouraging, so the policy was extended; Taobao.com continued to be free for three years

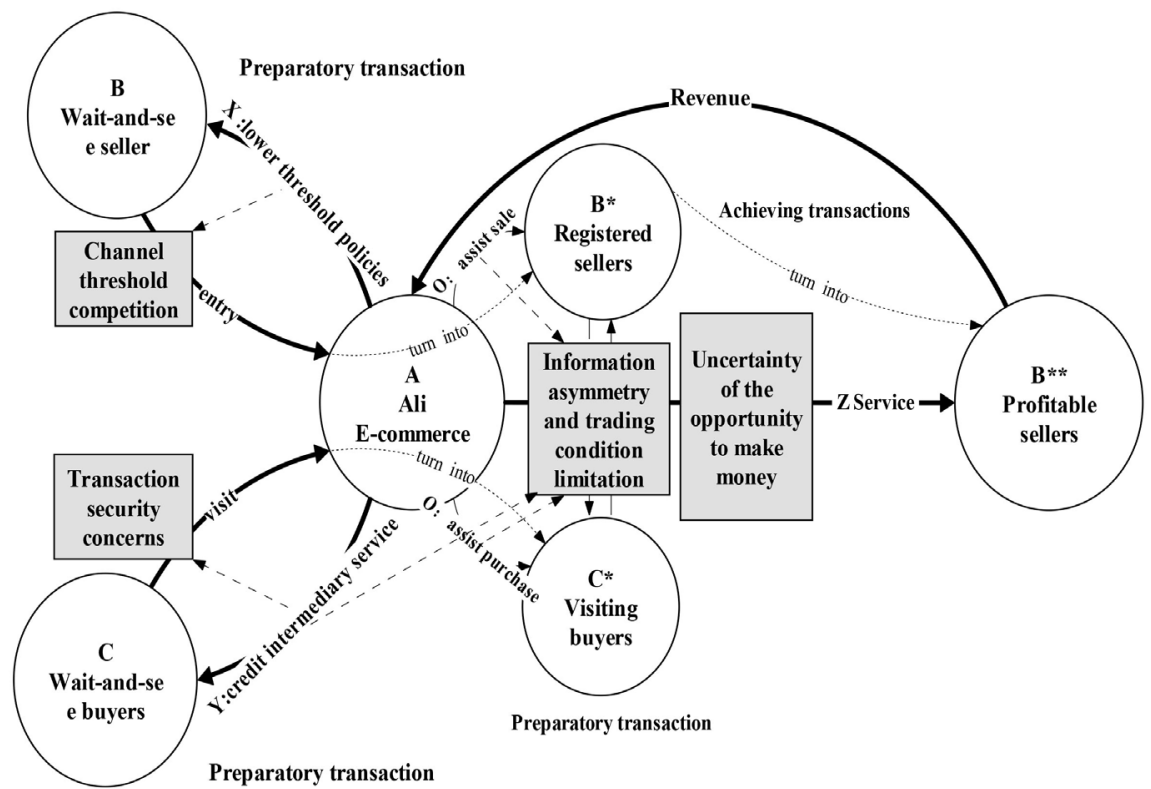

Figure 2. Ali E-commerce established a complete business system through transaction obstacle governance. 
Table 2. Examples of transaction obstacles in all the sub-transactions.

\begin{tabular}{|c|c|c|}
\hline Case & Code & Examples of original evidence \\
\hline $\begin{array}{c}\mathrm{A}-\mathrm{B} \\
\text { subcase }\end{array}$ & $\begin{array}{l}\text { Channel threshold } \\
\text { competition (CTC) }\end{array}$ & $\begin{array}{l}\text { In terms of } \mathrm{C} 2 \mathrm{C} \text { websites dominated by individual auctions, } \\
\text { popularity determines the possibility of trading, which is } \\
\text { the same as the shopping mall model. Therefore, } \\
\text { China's } \mathrm{C} 2 \mathrm{C} \text { firms need to make the cake bigger together. } \\
\text { But if they continue to charge fees for login and transaction, } \\
\text { it will discourage many people who want to try online } \\
\text { transactions and minimize the cost of opening a shop, } \\
\text { because they are facing a costly attempt. A C2C website, } \\
\text { to enlarge revenue, should open door to welcome any } \\
\text { guest (Li, 2004, in Chinese). } \\
\text { Tongyu Sun, general manager of taobao.com, said it all } \\
\text { depended on the market and the industry... Premature } \\
\text { charges can only shackle and hinder the normal } \\
\text { development of China's individual e-commerce; taobao.com } \\
\text { again called on eBay China and other channels to take the } \\
\text { same free strategy (Alibaba Group, 2005, in Chinese). }\end{array}$ \\
\hline $\begin{array}{c}\mathrm{A}-\mathrm{C} \\
\text { subcase }\end{array}$ & $\begin{array}{l}\text { Transaction security } \\
\text { concerns (TSC) }\end{array}$ & $\begin{array}{l}\text { In the early development stage of China's e-commerce, } \\
\text { the transaction process suffered from the existence of } \\
\text { fraudulent bankcards and counterfeit products, } \\
\text { which plagued sellers and buyers, respectively } \\
\text { (Kwak, Zhang, \& Yu, 2019). }\end{array}$ \\
\hline $\begin{array}{l}\mathrm{B}^{*} \text { - } \mathrm{C}^{*} \\
\text { subcase }\end{array}$ & $\begin{array}{l}\text { Information asymmetry } \\
\text { and trading condition } \\
\text { limitation (IATCL) }\end{array}$ & $\begin{array}{l}\text { Every day's huge information recorded by taobao.com } \\
\text { shows that information asymmetry is inevitable. First, } \\
\text { there are a wide range of commodities on the C2C platform, } \\
\text { so consumers are often confused in their choice and thus } \\
\text { cannot buy satisfying commodities. This phenomenon also } \\
\text { produces two adverse consequences: the sellers providing } \\
\text { genuine products are squeezed by the sellers selling } \\
\text { defective products out of the competitive market in price } \\
\text { wars; having suffered from inferior commodities, the buyers } \\
\text { produce doubts on seller, and thereby abandon purchase } \\
\text { when encountering congener again even if they are } \\
\text { true articles (Zhou, 2012: pp. 137-140, in Chinese). }\end{array}$ \\
\hline $\begin{array}{l}A-B^{* *} \\
\text { subcase }\end{array}$ & $\begin{array}{l}\text { Uncertainty of the } \\
\text { opportunity to make } \\
\text { money (UOMM) }\end{array}$ & $\begin{array}{l}\text { Our marketing customers are typically brand owners, } \\
\text { distributors and merchants who are sellers on our } \\
\text { marketplaces. Marketing customers do not have long-term } \\
\text { marketing commitments with us. The price a merchant is } \\
\text { willing to pay for online marketing services generally depends } \\
\text { on its expected GMV, profit margins and lifetime value of } \\
\text { customers derived from such marketing investment. If those } \\
\text { services do not generate the rate of return the seller expects or } \\
\text { rates that are competitive to alternatives, the seller may } \\
\text { reduce its spending on the marketing services we offer } \\
\text { (Alibaba Group, 2015). }\end{array}$ \\
\hline
\end{tabular}

from 2005 (see Table 3). As a result, by the end of March 2009, Ali-Ecommerce have attracted 40.25 million registered users (Anwar, 2017), which was almost near the total amount of 43 million SMEs at that time in China.

The second one is "initiation of inclusive credit intermediary services (IICTSs)", the launch of Alipay, which provides non-discriminatory inclusive credit intermediary arrangements for consumers. Alipay guarantees that consumers 
Table 3. An example of focused coding.

\begin{tabular}{|c|c|c|c|}
\hline Case & $\begin{array}{c}\text { Transaction } \\
\text { obstacle }\end{array}$ & Core governance measures & Governance effects \\
\hline $\begin{array}{c}\text { A-B } \\
\text { subcase }\end{array}$ & $\mathrm{CTC}^{\mathrm{a}}$ & $\begin{array}{l}\text { ILTPs }^{\#} \\
\text { In May 2003,Taobao Marketplace } \\
\text { was founded, at the same time it } \\
\text { announced the free entry policy } \\
\text { In October 2005, additional 3-year } \\
\text { free entry policy was announced }\end{array}$ & $\begin{array}{l}\text { Effectively repelled } \\
\text { competitors and attracted } \\
\text { many businesses (sellers) }\end{array}$ \\
\hline $\begin{array}{c}\text { C-B } \\
\text { subcase }\end{array}$ & $\mathrm{TSC}^{\mathrm{b}}$ & $\begin{array}{l}\text { IICISs }^{\dagger} \\
\text { In October 2003, Alipay service } \\
\text { was launched and then inclusive } \\
\text { credit intermediary service was } \\
\text { introduced into China } \\
\text { In December 2004, Alipay was spun } \\
\text { off from taobao.com and operated } \\
\text { independently } \\
\text { In February 2005, Alipay was } \\
\text { upgraded with a } \\
\text { "full compensation" system }\end{array}$ & $\begin{array}{l}\text { Greatly dispelled the worry } \\
\text { of wait-and-see buyers and } \\
\text { attracted them successfully }\end{array}$ \\
\hline $\begin{array}{c}\mathrm{B}^{\star} \text { - } \mathrm{C}^{\star} \\
\text { subcase }\end{array}$ & IATCL $^{c}$ & $\begin{array}{l}\text { PMDDTSs" (include assisting } \\
\text { purchase and assisting sale) } \\
\text { In March 2002, "chengxin tong" } \\
\text { (credit certificate)was launched } \\
\text { for sellers and buyers in China } \\
\text { In June 2008, "chengxin tong" } \\
\text { (credit certificate)for individuals } \\
\text { was launched } \\
\text { In November 2003, Tradelink was } \\
\text { launched to allow buyers and sellers } \\
\text { to communicate in real time } \\
\text { through the Internet } \\
\text { In July 2004, Aliwangwang, a PC } \\
\text { version of communication software } \\
\text { that allows buyers and sellers to } \\
\text { communicate with each other by } \\
\text { instant text, voice and video } \\
\text { was released } \\
\text { In November 2007, Ali mom, } \\
\text { an online marketing technology } \\
\text { platform was established } \\
\text { In October 2007, Alibaba Finance } \\
\text { successfully lent the first online } \\
\text { guaranteed loan } \\
\text { In August 2009, "Ali loan" was } \\
\text { expanded with China construction } \\
\text { bank in zhejiang and Shanghai } \\
\text { In September 2009, Aliyun } \\
\text { was founded } \\
\text { In December 2009, the acquisition } \\
\text { of China wanwang, strengthening } \\
\text { Ali E-commerce's ability to provide } \\
\text { additional Internet infrastructure } \\
\text { services to domestic small } \\
\text { businesses was completed }\end{array}$ & $\begin{array}{l}\text { Effectively provided } \\
\text { comprehensive assistance } \\
\text { for buyers and sellers, helping } \\
\text { them to gradually overcome } \\
\text { information asymmetry } \\
\text { obstacles and trading } \\
\text { condition limit, and then } \\
\text { promoted the formation of } \\
\text { online trading habits in China }\end{array}$ \\
\hline
\end{tabular}




\section{Continued}

\begin{tabular}{|c|c|c|c|}
\hline $\begin{array}{c}\mathrm{A}-\mathrm{B}^{\star *} \\
\text { subcase }\end{array}$ & $\mathrm{UOMM}^{\mathrm{d}}$ & $\begin{array}{l}\text { The combination of the above ILTPs, } \\
\text { IICISs and PMDDTSs } \\
\text { (including } \\
\text { "assisting sale" and } \\
\text { "assisting purchase") }\end{array}$ & $\begin{array}{l}\text { Effectively overcame the } \\
\text { systematic transaction } \\
\text { obstacles and finally } \\
\text { integrated all the } \\
\text { sub-transactions into one } \\
\text { business system }\end{array}$ \\
\hline
\end{tabular}

${ }^{a}$ Channel threshold competition; ' $\mathrm{Transaction}$ security concerns; 'Information asymmetry and trading condition limitation; ${ }^{\mathrm{d}}$ Uncertainty of the opportunity to make money. "Implementation of the lower threshold policies; ${ }^{\dagger}$ Initiation of inclusive credit intermediary services; ${ }^{*}$ Providing multi-dimensional deep trading services.

pay the sellers only after receiving the goods, thus greatly improves the safety of shopping. This initiative makes the biggest contribution to Ali E-commerce to establish its market legitimacy (Kwak, Zhang, \& Yu, 2019). In essence, it is a powerful tool to help the buyers and sellers, especially the former, to remove the TSC (mainly applied to solve the problem of C-A transaction, but also $\mathrm{B}^{\star}-\mathrm{C}^{\star}$ transaction). Afterwards, Ali E-commerce further keeps on upgrading Alipay services, introducing compensation mechanism to consumers to help them to eliminate TSC (see Table 3).

The third one is "providing multi-dimensional deep trading services (PMDDTSs)" providing both the buyers and the sellers multi-dimensional and deep-level services involving information disclosure, qualification verification, instant messaging, financial management, network management, advertising, credit, logistics, etc., mainly from the dimension of "assisting purchase" and of "assisting sale". There is no doubt that this type of measures can help the registered buyers and the visiting sellers to overpass the stumbling block of IATCL. In detail, Ali E-commerce once invents most abundant initiatives in this regard, e.g. it once launches many assisting services such as the TrustPass, Trade Manager, Aliwangwang, Alimama, Ali Loan, Aliyun, etc. In consequence, Ali E-commerce has gradually turned the difficult online trade into a kind of viable and convenient business (see Table 3).

These three types of initiatives combine and constitute the full Ali E-commerce service system, enabling Ali E-commerce to overcome the last one lethal stumbling block UOMM, to provide profit-making opportunities to the registered sellers (that is the $\mathrm{Z}$ service in Figure 2), and then to obtain revenue in return. On the other hand, they also constitute the main projects of Ali E-commerce entrepreneurial process. The data shows (see Table 3 ) that these initiatives always aim at the corresponding transaction obstacles and evolve through adjustment, optimization, expansion and coordination, which shows that the measures are of high-degree consciousness, order, logic and evolution. As a result, they finally formed a set of orderly management mechanism. All in all, the entrepreneurial process of Ali E-commerce in essence is a process of battle against stumbling blocks.

Once transaction obstacles can be detected, then the conscious and systematic 
governance activities implemented around overcoming the transaction obstacles may ultimately help the entrepreneurs to overcome or remove the stumbling blocks and lead to success. In this study, the conscious and systematic governance activities are summarized as "transaction obstacle governance (TOG)". Obviously, only when conscious cognition, managerial awareness and systemic governance methods are interweaved together against transaction obstacles, can those managerial activities be called transaction obstacle governance.

So far, this study has extracted two key constructs-transaction obstacle (TO) and transaction obstacle governance (TOG), from Ali E-commerce's practices. The former is a kind of important obstructive factor in the process of starting a business; the latter is a set of systematic measures for entrepreneurs to consciously overcome and control the obstructive factor. Therefore they are intimately associated with each other. The more transaction obstacles are identified, the more transaction obstacle governance is needed. Figure 2 is a graphic analysis of the details of Ali E-commerce's transaction obstacle governance process. From the perspective of process, along with those governance measures overcome transaction obstacles either individually or in combination in preparatory transaction $\mathrm{A}-\mathrm{B}, \mathrm{A}-\mathrm{C}, \mathrm{B}^{*}-\mathrm{C}^{*}$, the transaction obstacle of UOMM in achieving transaction $\mathrm{A}-\mathrm{B}^{* *}$ will also be overcome. Thus, Ali E-commerce is able to govern all the major transaction obstacles, build an effective trading system and finally achieve successful entrepreneurship (see the complete trading system in Figure 2 ). By further refining and summarizing Figure 2, this study gets a new conceptual model of entrepreneurial process shown in Figure 3, which displays the functions of transaction obstacle governance.

To sum up, Ali E-commerce's entrepreneurial process is: by means of transaction obstacle governance, the preparatory transactions are built firstly, and then the achieving transaction is accomplished. It is transaction obstacle governance that operates through Ali E-commerce's entrepreneurial process and ultimately establishes its overall business system. In conclusion, the effectiveness of transaction obstacle governance determines the success of Ali E-commerce's entrepreneurship.

\section{Further Discussions}

The above findings raise new issues and bring a new perspective for people to discuss entrepreneurship.

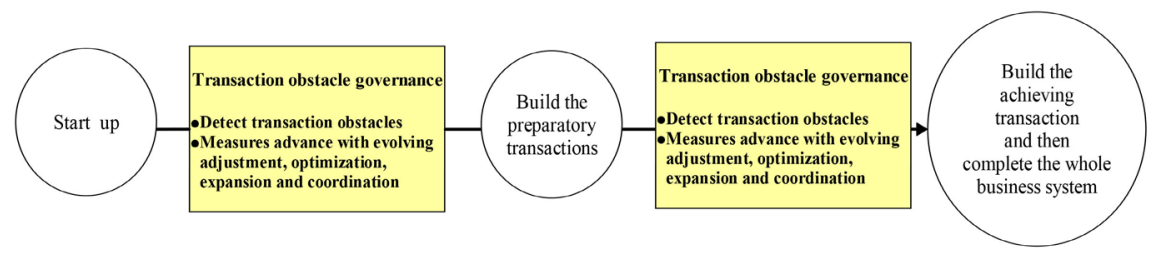

Figure 3. A new entrepreneurial process model based on transaction obstacle governance. 
The first question is: are there always transaction obstacles in any entrepreneurial process?

The question first relates to whether the entrepreneurial process can be viewed from the perspective of transaction. There are two classic theories that support the transaction view. First, the classic economic theory holds that enterprise organization is a production function $\mathrm{F}(\mathrm{K}, \mathrm{L})=\mathrm{Q}$ that integrates input and output, namely, an enterprise is an integrated structure composed of input factor market and product market; in view of the fact that both the input factor market and the product market are all trading venues, an enterprise organization is essentially a structure formed by the combination of input factor transactions and product transactions. In the case of Ali E-commerce, its business system demonstrates as a combination of preparatory transaction and achieving transaction, which is exactly this kind of structure. This not only illustrates that Ali E-commerce is a typical enterprise sample, but also reflects it is inevitable that an enterprise exists as a transaction structure. Second, institutional economic theory also holds that transaction is the basic unit of economic activities (including enterprise activities) (Commons, 1997), and enterprise is the aggregation of transaction contracts (Coase, 1937; Williamson, 1991; Dyer, 1996; Hansmann, 1996; Gulati, Lawrence, \& Puranam, 2005; Jacobides \& Billinger, 2006). These theories show that enterprises are essentially transaction systems, so it is reasonable and appropriate to regard entrepreneurship as the process of establishing transaction systems.

Furthermore, this question also relates to whether it is sure that in any transaction process there exist transaction obstacles. Transaction cost theory and contract economic theory also give a positive answer. When analyzing the cause of transaction cost, transaction cost theory points out that the information asymmetry, opportunism tendency, bounded rationality and various uncertainties that widely exist in transaction all constitute threats and obstacles to transaction (Williamson, 1991). The contract economic theory insists more firmly that any transaction is incomplete contract, so there must be destructive factors that make perfect transaction absolutely impossible (Hart, 1995; Langlois, 2003), from which it can be inferred that there must be transaction obstacles in any transaction.

The natural deductive judgment from above theory is that it is certain that any entrepreneurial process includes transaction obstacles. The only difference is that the location, the cause, the strength, the mutual link, the influence and other aspects of each transaction obstacle encountered by each entrepreneur may vary more or less.

In the case of Ali E-commerce, although that time in China witnessed some special social and economic factors such as the infant stage of e-commerce, fierce competition in the same sector, and the low level of social mutual trust, etc. to bothering entrepreneurship, they are only the external conditions that fertilize the transaction obstacles, rather than direct obstacle-making factors. In 
fact, the real direct driving forces in Ali E-commerce's transactions is still human being's economic rationality as well as the non-uniformity nature of transaction itself pointed out by classic theory. Therefore, as long as these basic attributes of transaction are eternal around the world, it can be said that the transaction obstacles that Ali E-commerce encountered will also exist in other enterprises.

The second question is: do all kinds of entrepreneurial obstacles belong to transaction obstacles?

Since there are no systematic or authoritative conclusions about the categories of various obstacles encountered in the process of starting a business, it is impossible to tell whether they all belong to transaction obstacles. However, as mentioned above, in the case of Ali E-commerce, all the key entrepreneurial obstacles observed in this study occur in the transaction processes, so they are all transaction obstacles. This suggests that any obstacle can be regarded as a transaction obstacle as long as it occurs in a transaction process, or, any obstructive factor can be regarded as a transaction obstacle as long as it objectively hinders any transaction.

Therefore, all kinds of obstacles found in entrepreneurship can still be identified as transaction obstacles as long as they disturb the transaction, even if they originate from non-transaction occasions such as the $\mathrm{R} \& \mathrm{D}$ node, production link or the outer surroundings. For instance, because transactions always occur in some specific environment, some environmental factors may cause or act as the kind of obstacles that negatively affect the transactions; in case of this, these obstacles should be identified as transaction obstacles. As Fogel et al. (2006) say, institutional factors such as weak protection of property rights as well as cumbersome and expensive regulations are likely to inhibit the entrepreneurs from obtaining capital through financial transactions. Bhosale \& Bhola (2014) point out that industrial patterns and social movements such as the power of large enterprises, labor union shocks, etc. may also cause some difficulties in various entrepreneurial transactions. All these situations illustrate what transaction obstacles mean.

In this sense, many entrepreneurial obstacles observed from the perspective of institutional environment may hinder the specific transaction when they are observed from the perspective of transaction, so they can be classified as transaction obstacles. Therefore, the concept of transaction obstacle provides a broad vision for people to understand the obstacles in entrepreneurship.

The third question is: does transaction obstacle governance have to be the main project in the process of entrepreneurship?

Ali E-commerce has encountered big stumbling blocks in its all major transactions; so its several major transaction obstacles are very harmful to its entire business system in structure, and therefore have to be focused on to tackle. Spontaneously, transaction obstacle governance has become the main project of Ali E-commerce's entrepreneurship. However, logically speaking, any specific 
entrepreneurial process has its own unique context. For instance, in the mature markets of well-developed economies, there are many favorable factors helping entrepreneurship, such as stable and friendly institutional environment, high degree of integrity in social interactions, convenient and efficient information exchange, etc.; therefore, transaction obstacle in the process of entrepreneurship may be relatively trivial, and then the entrepreneurial process does not have to be centered on the governance of transaction obstacles. On the contrary, under the circumstances in which people's selfish opportunism, transaction complexity, transaction contract incompleteness, etc. are rampantly epidemic, strictly speaking, it is almost impossible to start a business without encountering transaction obstacles. Once these transaction obstacles seriously impede the entrepreneurship, transaction obstacle governance is no doubt extremely necessary.

Based on all the above case inductions and logic deductions, this study draws the following propositions:

1) The establishment of a systematic transaction structure is indispensable to any entrepreneurship. In the process, there may exist major transaction obstacles that threaten entrepreneurial success.

2) The entrepreneurs should completely, accurately and consciously identify the transaction obstacle when they perceive that there are significant obstructions in entrepreneurship.

3) The consciousness of transaction obstacle governance (CTOG) is an important and beneficial management mindset and entrepreneurial awareness. Transaction obstacle governance is either a beneficial entrepreneurial idea or an important controllable variable in the process of entrepreneurship. Therefore, the more effective transaction obstacle governance is, the bigger the probability of entrepreneurial success is.

\section{Conclusion}

In a time when entrepreneurship is becoming more and more popular and important all around the world, higher survival rate of the startups means a lot. Though previous entrepreneurship theories have found varied methods to assist the entrepreneurs from many different perspectives, astonishingly, the stumbling block, a common phenomenon, which always exists in the business process of any startup of any country and any time, seems to be thoroughly overlooked. However, its impact upon any startup is always objective and unavoidable; thus having no idea of it certainly is an unfortunate matter to both academics and entrepreneurs. This paper tries to complement this gap, focusing on the problem of transaction obstacle in the process of starting a business, and thereby introduces a new perspective for the study of entrepreneurial process. As the initial exploration in this field, this paper finds a kind of specific stumbling block, i.e. transaction obstacle (TO), which extensively exists in the growing process of a nascent business, and puts forward the concept of transaction obstacle governance (TOG). 
Accordingly, this research contributes some new ideals to enterprise management from both the theoretical perspective and practical perspective.

In theory, this paper takes the lead in paying attention to the problem of transaction obstacle in the process of starting a business, introducing the perspective of entrepreneurial process to observe those obstructive factors distributed among a business' structure, which preliminarily complements prior researches, such as Bitzenis \& Nito (2005), Fogel et al. (2006), Bhosale \& Bhola (2014), etc., which emphasize more on environment analysis than on the business process itself. Based on this novel perspective in observing obstructive factors, this paper fulfills systematic screening upon the business structure of a startup, and finally develops the novel construct of transaction obstacle (TO), which explicitly generalizes the obstructive phenomena that have been impeding the growing of a nascent business. By means of this construct, researchers may avoid underestimating the impact of those obstructive factors in entrepreneurship, so that it gives startups more deliberate and effective directions. Logically, once transaction obstacles are bridged over, it is a high probability event for any business to run smoothly. From this point, this paper not only adds new knowledge to the entrepreneurial process theory, but also may shed lights on the general enterprise management theory.

In practice, this study suggests that entrepreneurs should pay more attention to the vital factors that hinder the key transactions and cope with them properly, which renders entrepreneurs a new managerial perspective and endows them more operable managerial arms to achieve triumph. Suppose that more and more entrepreneurs can establish the consciousness of transaction obstacle governance (TOG), and then identifying, diagnosing and finding feasible prescriptions to govern the transaction obstacles will become major agenda in their entrepreneurships. Except the case firm Ali E-commerce, it seems that this kind of entrepreneurial practice rarely occurs till now. If this paper can enlighten the entrepreneurs to gradually exercise transaction obstacle governance, and then more startups may benefit from it, as a result, a new pattern of entrepreneurship in the feature of managing obstructive factors may gradually demonstrates its significance.

The limitations of this study are as follows: First, because it may be an initial research on the problem of transaction obstacle, this study only puts forward the idea of transaction obstacle governance and points out its significance without advancing it in detail. In fact, the contents of governing the transaction obstacle must be multitudinous; there is a lot research space upon this topic. This regret may only be redeemed in the future. Second, this study only involves the problem of transaction obstacle, but does not touch on other possible obstacle factors in entrepreneurship. However, both of them surely always exist together in the real world, so the latter shouldn't be neglected. Besides, it is necessary and interesting for people to know how those consensus factors discovered by extant entrepreneurial process theories function together with transaction obstacles; yet this seems to be a huge project that is not appropriate to discuss here. Naturally, 
this topic also awaits the real insights of other experts and scholars. Third, this work develops the constructs through analyzing and comparing multiple transaction units in a single entity. Although this is a more economical approach than directly contrasting several different entities, the latter may have more reliability and therefore pretty much deserve being adopted in future research.

It is worth noting that, though having the above limitations, the constructs this paper discloses may still be rather robust. Evidently, transaction obstacle is as old as the transaction itself; it is the natural and eternal companion of the transaction behavior, and also the direct cause of the transaction cost. Since transaction obstacle is an objective existence independent from man's will, it is impossible for any enterprise to bypass it; therefore, its cognitive value is probably no less important than that of process, time, knowledge and other managerial concepts. However, though there are some mature ideas and theories such as process management, time management, and knowledge management in the study of management, transaction obstacle has not been taken seriously so far, and the concept, consciousness and theory of transaction obstacle governance are absent as well. This is an obvious flaw in present management research. In this sense, this study may bring some fresh thinking into management study through first putting forward the concept of transaction obstacle governance; this concept may not only inspire the entrepreneurship research, but also imply an interesting topic in the entire enterprise management research.

In term of future work, the authors will endeavor to develop scales for both transaction obstacle and transaction obstacle governance, and then through exploring research try to find more potential hypotheses based on these constructs. Since the constructs have been captured through this work, the authors suggest both academics and entrepreneurs continue to test and revise them until them become scientific concepts. To push on this work, the authors will also exercise empirical research to verify those potential hypotheses based on these two novel constructs, and expect to augment more new knowledge to entrepreneurship theory.

\section{Acknowledgements}

Yu Cheng acknowledges the support by the National Natural Science Foundation of China (No. 70972109), the support by Fujian Scholarship for Studying Abroad, and the support by Durham University Business School. Jun Wen acknowledges the support by the Research Fund Project for Young Teachers of School of Economics and Management, Nanjing University of Science and Technology (JGQN1704), the support by China Scholarship Council, and the support by Durham University Business School. Yaping Xie acknowledges the support by Fujian Scholarship for Studying Abroad.

\section{Conflicts of Interest}

The authors declare no conflicts of interest regarding the publication of this paper. 


\section{References}

Alibaba Group (2005). Taobao.com Continues to Provide Free Services for Three Years Investing 1 Billion to Create 1 Million Jobs. https://www.alibabagroup.com/cn/news/press_pdf/p051020.pdf

Alibaba Group (2015). Annual and Transition Report (Foreign Private Issuer). https://otp.investis.com/clients/us/alibaba/SEC/sec-outline.aspx?FilingId=10777543\&C $\mathrm{ik}=0001577552 \&$ PaperOnly $=0 \&$ HasOriginal $=1$

Alibaba Group (2018). ESG Report 2018. https://esg.alibabagroup.com/ui/pdfs/Alibaba-ESG-Report-2018.pdf

Alibaba Group (2019). December 2019 Quarterly Results Announcement. https://www.alibabagroup.com/cn/ir/presentations/pre200213.pdf

Anwar, S. T. (2017). Alibaba: Entrepreneurial Growth and Global Expansion in B2b/B2c Markets. Journal of International Entrepreneurship, 15, 366-389. https://doi.org/10.1007/s10843-017-0207-2

Bhosale, M. B., \& Bhola, S. S. (2014). Obstacles in Growth of Entrepreneurship. International Journal of Research in Commerce, IT \& Management, 4, 12-13.

Bitzenis, A., \& Nito, E. (2005). Obstacles to Entrepreneurship in a Transition Business Environment: The Case of Albania. Journal of Small Business and Enterprise Development, 12, 564-578. https://doi.org/10.1108/14626000510628234

Bleier, A., Harmeling, C. M., \& Palmatier, R. W. (2018). Creating Effective Online Customer Experiences. Journal of Marketing, 83, 98-119. https://doi.org/10.1177/0022242918809930

Bygrave, W. D. (1997). The Portable MBA in Entrepreneurship. New York: John Wiley \& Sons.

Cacciotti, G., Hayton, J. C., Mitchell, J. R., \& Giazitzoglu, A. (2016). A Reconceptualization of Fear of Failure in Entrepreneurship. Journal of Business Venturing, 31, 302-325. https://doi.org/10.1016/j.jbusvent.2016.02.002

Cardoni, A., Kiseleva, E., \& Lombardi, R. (2020). A Sustainable Governance Model to Prevent Corporate Corruption: Integrating Anticorruption Practices, Corporate Strategy and Business Processes. Business Strategy and the Environment, 29, 1173-1185. https://doi.org/10.1002/bse.2424

Cartner, W. (1985). A Conceptual Framework for Describing the Phenomenon of New Venture Creation. Academy of Management Review, 4, 695-705. https://doi.org/10.2307/258039

Chen, L., Nan, G., \& Li, M. (2018). Wholesale Pricing or Agency Pricing on Online Retail Platforms: The Effects of Customer Loyalty. International Journal of Electronic Commerce, 22, 576-608. https://doi.org/10.1080/10864415.2018.1485086

Cheng, Y. (2004). Transaction Analysis: Innovatory Paradigm in the Research of Enterprise Activities. China Industrial Economy (In Chinese), 5, 97-104.

Chow, D. C. K. (2020). Alibaba, Amazon, and Counterfeiting in the Age of the Internet. Northwestern Journal of International Law \& Business, 40, 157-202.

Churchill, N. C., \& Lewis, V. L. (1983). The Five Stages of Small Business Growth. Harvard Business Review, 5, 30-50.

Coase, R. H. (1937). The Nature of the Firm. Economica, New Series, 4, 386-405. https://doi.org/10.1111/j.1468-0335.1937.tb00002.x

Commons, J. R. (1997). Institutional Economics (1) (S. Sh. Yu, Trans., pp. 45-49). Beijing: The Commercial Press. 
Dewald, J., \& Bowen, F. (2010). Storm Clouds and Silver Linings: Responding to Disruptive Innovations through Cognitive Resilience. Entrepreneurship Theory and Practice, 34, 197-218. https://doi.org/10.1111/j.1540-6520.2009.00312.x

Dyer, J. H. (1996). Does Governance Matter? Keiretsu Alliances and Asset Specificity as Sources of Japanese Competitive Advantage. Organization Science, 7, 649-666.

https://doi.org/10.1287/orsc.7.6.649

Eisenhardt, K. M. (1989). Building Theories from Case Study Research. Academy of Management Review, 14, 532-550. https://doi.org/10.5465/amr.1989.4308385

Eisenhardt, K. M. (1991). Better Stories and Better Constructs: The Case for Rigor and Comparative Logic. Academy of Management Review, 16, 620-627. https://doi.org/10.5465/amr.1991.4279496

Eisenhardt, K. M., \& Graebner, M. E. (2007). Theory Building from Cases: Opportunities and Challenges. Academy of Management Journal, 50, 25-32. https://doi.org/10.5465/amj.2007.24160888

Fogel, K., Hawk, A., Morck, R., \& Yeung, B. (2006). Institutional Obstacles to Entrepreneurship. In M. Casson, B. Yeung, A. Basu, \& N. Wadeson (Eds.), The Oxford Handbook of Entrepreneurship. Oxford: Oxford University.

Gilbert, C. G. (2005). Unbundling the Structure of Inertia: Resource versus Routine Rigidity. Academy of Management Journal, 48, 741-763. https://doi.org/10.5465/amj.2005.18803920

Gulati, R., Lawrence, P. R., \& Puranam, P. (2005). Adaptation in Vertical Relationships: Beyond Incentive Conflict. Strategic Management, 26, 415-441. https://doi.org/10.1002/smj.458

Han, W., Yang, J., Chen, F. W., Zhang, Y. L., \& Deng, Y. (2017). How to Establish tie Portfolio to Improve Performance for Entrepreneurial Firms: Case Study Based on Interaction of Structure and Re-Sources. Management World (In Chinese), 10, 130-188. https://doi.org/10.3390/su10103815

Hansmann, H. (1996). The Ownership of Enterprise. Cambridge, MA: Harvard University Press.

Hart, O. (1995). Firms, Contracts, and Financial Structure. Oxford, UK: Oxford University Press. https://doi.org/10.1093/0198288816.001.0001

Hu, J. L., \& Chang, Y. C. (2019). The W-Theory of Five Elements for Innovative Business Activities with a Case Study of Alibaba Corporation. Journal of Management Research, 19, 173-179.

Jacobides, M. G., \& Billinger, S. (2006). Designing the Boundaries of the Firm: From "Make, Buy, or Ally" to the Dynamic Benefits of Vertical Architecture. Organization Science, 17, 249-261. https://doi.org/10.1287/orsc.1050.0167

Javaid, O., \& Hyder, I. (2018). Using Eisenhardt's Method to Study Ethnic Entrepreneurial Communities. South Asian Journal of Management Sciences, 12, 25-45. https://doi.org/10.21621/sajms.2018121.02

Kollmann, T., Stöckmann, C., \& Kensbock, J. M. (2017). Fear of Failure as a Mediator of the Relationship between Obstacles and Nascent Entrepreneurial Activity: An Experimental Approach. Journal of Business Venturing, 32, 280-301. https://doi.org/10.1016/j.jbusvent.2017.02.002

Kwak, J., Zhang, Y., \& Yu, J. (2019). Legitimacy Building and e-Commerce Platform Development in China: The Experience of Alibaba. Technological Forecasting \& Social Change, 139, 115-124. https://doi.org/10.1016/j.techfore.2018.06.038

Langlois, R. N. (2003). The Vanishing Hand: The Changing Dynamics of Industrial Ca- 
pitalism. Industrial and Corporate Change, 12, 351-385.

https://doi.org/10.1093/icc/12.2.351

Li, M. (2004). Taobao.com Calls for Free-Entry C2C Market in China. Science and Technology Daily (In Chinese).

Lin, S., \& Wang, S. (2019). How Does the Age of Serial Entrepreneurs Influence Their Re-Venture Speed after a Business Failure? Small Business Economics, 52, 651-666. https://doi.org/10.1007/s11187-017-9977-0

Lü, L. (2014). Application of Inductive Logic in Management Case Study: An Analysis of Award-Wining Papers in AMJ. Nankai Business Review, 1, 151-160.

Moore, C. F. (1986). Understanding Entrepreneurial Behavior: A Definition and Model. In Academy of Management Best Papers Proceedings (pp. 66-70). Briarcliff Manor, NY: Wiley. https://doi.org/10.5465/ambpp.1986.4978712

Morris, M. H., Kkuratko, D. F., Schindehutte, M., \& Spivack, A. J. (2012). Framing the Entrepreneurial Experience. Entrepreneurship Theory and Practice, 36, 11-40. https://doi.org/10.1111/j.1540-6520.2011.00471.x

Santos, F. M., \& Eisenhardt, K. M. (2005). Organizational Boundaries and Theories of Organization. Organization Science, 16, 491-508. https://doi.org/10.1287/orsc.1050.0152

Sellami, M., Maamar, Z., Lefebvre, S., \& Faci, N. (2019). Logs and Enterprise Networks for Over-Coming Obstacles in Business Processes. Computing, 101, 263-288. https://doi.org/10.1007/s00607-018-00696-y

Steininger, D. M. (2019). Linking Information Systems and Entrepreneurship: A Review and Agenda for IT-Associated and Digital Entrepreneurship Research. Information Systems Journal, 29, 363-407. https://doi.org/10.1111/isj.12206

Su, X., Liu, S., Zhang, S., \& Liu, L. (2020). To Be Happy: A Case Study of Entrepreneurial Motivation and Entrepreneurial Process from the Perspective of Positive Psychology. Sustainability, 12, 584. https://doi.org/10.3390/su12020584

Timmons, J. A. (1999). New Venture Creation (5th ed.). Boston, MA: McGraw-Hill.

Van Burg, E., \& Romme, A. G. L. (2014). Creating the Future Together: Toward a Framework for Research Synthesis in Entrepreneurship. Entrepreneurship Theory and Practice, 38, 369-397. https://doi.org/10.1111/etap.12092

Williamson, O. E. (1991). Strategizing, Economizing and Economic Organization. Strategic Management Journal, 12, 75-94. https://doi.org/10.1002/smj.4250121007

Zhou, J. H. (2012). Alibaba Management Mode (pp. 137-140). Hangzhou: Zhejiang People's Publishing House. 